\title{
The importance of use of the FSFI questionnaire in gynecology and venerology: a pilot study
}

\author{
Grażyna Jarząbek-Bielecka, Katarzyna Plagens-Rotman², Małgorzata Mizgier³, Justyna Opydo-Szymaczek, \\ Ewa Jakubek ${ }^{5}$, Witold Kędzia ${ }^{1}$
}

${ }^{1}$ Division of Developmental Gynaecology and Sexology, Department of Perinatology and Gynaecology, Poznan University of Medical Sciences, Poznan, Poland

${ }^{2}$ Hipolit Cegielski State University of Applied Sciences, Gniezno, Poland

${ }^{3}$ Department of Dietetics, Faculty of Physical Culture in Gorzow Wielkopolski, Poznan University of Physical Education in Poznan, Poland

${ }^{4}$ Department of Pediatric Dentistry, Poznan University of Medical Sciences, Poznan, Poland

${ }^{5}$ Department of Organization and Management in Healthcare, Poznan University of Medical Sciences, Poznan, Poland

Adv Dermatol Allergol 2021; XXXVIII (3): 480-485

DOI: https://doi.org/10.5114/ada.2021.107934

\begin{abstract}
Introduction: The Female Sexual Function Index (FSFI) is recognized as an excellent tool for assessing female sexuality and screening female sexual dysfunction, but it also has important venereological implications as sexually transmitted diseases result from human behaviour in the sexual sphere. It is influenced by socio-economic, psychological and cultural factors.

Aim: To present the results of an attempt to implement FSFI in gynaecological practice.

Material and methods: The study comprised 91 women aged 20-35 (mean: $24.3 \pm 4.0$ ) undergoing prophylactic gynaecological examinations. All of them voluntarily agreed to fill in the FSFI questionnaire, and provide data on weight, height, hormone treatments, the age of menarche and sexual initiation and information essential in health promotion and prevention, including the prevention of sexually transmitted diseases.

Results: The average age of the first sexual intercourse was $18.2 \pm 2.4$. The total FSFI score ranged from 3.8 to 35.1 points (mean: $27.4 \pm 6.5$ ). As many as $34.1 \%$ of the women presented with FSFI < 27.50, suggesting an increased risk of sexual dysfunction. Patients' age as well as the age of menarche were both negatively correlated with desire. The mean FSFI scores for almost all of the domains and the FSFI total score were higher for women taking oral contraceptives, although statistically significant differences were detected only for the orgasm domain.

Conclusions: A high percentage of sexually active Polish women presented with FSFI below the threshold, suggesting some grade of sexual dysfunction. Gynaecological and STI medical history should be extended to include issues related to female sexual function.
\end{abstract}

Key words: sexuality, women, gynaecology.

\section{Introduction}

According to the World Health Organization (WHO) definition, sexual health is a group of biological, emotional, intellectual and social aspects of sexual life, essential for positive personality development, communication skills and love. One of the most important issues in maintaining sexual health is sexually transmitted diseases (STD) prevention.
STDs arise from human behaviour that is influenced by socioeconomic, psychological and cultural factors. These diseases are a significant cause of concern for the health care and society in general. One of the risk factors is early sexual initiation. This element and at the same time the assessment of the quality of sexual life were assessed in a pilot study using The Female Sexual Function Index (FSFI). This questionnaire is therefore important in sexology, gynaecology, and venereology.

Address for correspondence: Katarzyna Plagens-Rotman, Hipolit Cegielski State University of Applied Sciences, 38 Stefana Wyszyńskiego St, 62-200 Gniezno, Poland, e-mail: plagens.rotman@gmail.com Received: 7.10 .2020 , accepted: 4.11 .2020$. 
It should be emphasized here that the number of sexually transmitted infections (STIS) between the age of 15 and 24 is almost $50 \%$ and is significantly associated with an early sexual debut, a high number of sexual partners, including casual sexual contacts and insufficient comprehensive sexuality education.

A preliminary assessment was made of the indicator of female sexual function and its association with sexual health and gynaecological practice.

WHO defines sexual health as a state of physical, mental and social well-being in relation to sexuality. It demands a respectful and positive approach to sexuality and sexual relationships, which is crucial for personality development, communication skills and love [1]. It is thus obvious that sexual dysfunctions may have a negative impact on the quality of life of individuals. Although multiple factors affecting human sexuality, such as biology, psychology, social environment, financial status, politics, culture, law, history and religion, have been discussed in the literature [2-4], epidemiological data on the prevalence of sexual dysfunctions are scarce [5].

Despite the progress in the area of gender equality, the epidemiology of sexual health including prevalence and risk factors for women's sexual health issues still remain a largely under-researched area $[4,5]$.

According to Pastwa-Wojciechowska and Izdebski, in $2005,8.6 \%$ of Polish people were not satisfied with their sexual life, including $4.7 \%$ assessing it as "rather bad", 2.6\% as "bad" and 1.3\% as "very bad" [6]. A questionnaire study carried out by Lew-Starowicz et al. found that $8 \%$ of Polish women aged 18-59 have never experienced an orgasm, 21\% complained about rare orgasms and 30\% about decreased sexual needs [7]. At the same time, Czajkowska et al. noted that in 2015 more than $30 \%$ of Polish women had sex a few times a week and more than a quarter of the subjects under study found the number of their sexual intercourses insufficient [8]. Therefore, it seems that there are good reasons for the further diagnosis of the quality of Polish women's sexual activity and identifying potential sexual health disorders during gynaecological examinations. For that purpose, the FSFI research tool can be used to supplement the medical history and physical examination [5]. Our study was conducted with the use of the current, revised version of the FSFI. The FSFI questionnaire can also be used in gynaecological practice, given that the assessment of sexual health and satisfaction is pivotal component of gynaecological and venereological practice [9].

\section{Aim}

Demonstrating the importance of using the FSFI questionnaire with a question about sexual initiation in medical practice (gynaecology, sexology, venereology).

\section{Material and methods}

The Ethical Committee of the Poznan University of Medical Sciences granted its approval for this study (Resolution no. 29/10, annex no. 614/19 of 15.05.19).

The subjects in the study were 91 women aged 20-35, who underwent gynaecological screening at the outpatient clinic of the Gynaecology and Obstetrics University Hospital in Poznan, Poland in 2013 and agreed to fill in an FSFI questionnaire related to their sexuality.

The FSFI questionnaire consists of 19 close-ended questions related to sexual activity within the 4 weeks prior to the examination and includes six domains: sexual desire (questions number 1-2), sexual arousal (questions number 3-6), lubrication (questions number 7-10), orgasm (questions number 11-13), satisfaction (questions number 14-16) and pain (questions number 17-19). Points are assigned for each answer (1-5 and 0-5 for questions 1-2 and questions 3-19, respectively), the sum of the scores for the domain is multiplied by the domain factor, the six domain scores are added up, and the total score may vary from 2.0 to 36.0 points. The Polish version of the questionnaire was validated and standardized for Polish women by Nowosielski et al. [10]. Initially, a score lower than 26.55 was considered to indicate the risk of a sexual dysfunction [11], and Polish authors now recommend a slightly higher threshold of 27.50 in the screening of Polish women [10].

They had been thoroughly informed about the confidentiality of the study. Only heterosexual women with the current sexual partner were included in the study. The history of sexual trauma and mental disorders, any general health problems and therapy potentially affecting sexual life, such as hyperandrogenism and hormonal medications other than contraceptives, were the exclusion criteria [12-16].

The FSFI was used as a research instrument and was extended to include information about the participants' age, body weight, height, age of menarche, the use of oral contraceptives and the age of the first sexual intercourse, as well as any history of STI.

\section{Statistical analysis}

Quantitative variables were described as the arithmetic mean, standard deviation (SD), the median, the lowest (min.) and the highest values (max.).

Due to the lack of normal distribution of the data, the Mann-Whitney non-parametric test was used to assess the differences between two independent groups. Interdependencies between quantitative variables were assessed with the use of Spearman's rank-order correlation coefficient. Statistical analysis was conducted with the use of Statistica 10PL software. A value of $p<0.05$ was considered significant. 


\section{Results}

In the preliminary interview, 108 females agreed to answer the questions. However, $16 \%$ of the participants (17 out of 108) did not fully complete the questionnaire (omitting the questions about sexual function and/or age of sexual initiation), although they had been assured of the anonymity of the study and despite giving informed consent to participate in it. It has to be noted that on returning the questionnaires, the women did not inform the researchers that their answers were incomplete. Therefore, in the course of further analysis, 17 questionnaires were excluded due to their incompleteness.

The age range of women in the sample was 20-35, mean $24.3 \pm 4.0$ years. The women's body mass index (BMI) ranged from 16.73 to $33.50 \mathrm{~kg} / \mathrm{m}^{2}$ (mean: $21.72 \pm 2.98 \mathrm{~kg} / \mathrm{m}^{2}$ ). The average age of menarche was $12.7 \pm 1.5$ (it occurred between 10 and 18 years). The average age of the first sexual intercourse was $18.2 \pm 2.4$ years (it ranged from 13 to 28 years of age). Thirty-seven (40.7\%) subjects of the study did not take oral contraceptives (Table 1). None of the women indicated that she was treated or diagnosed with any STD.

The total FSFI score varied from 3.8 to 35.1 points, with an average of $27.4 \pm 6.5$ points, ranging from 3.8 to 35.1 . Out of all the FSFI domains, the highest average score was reported for satisfaction (5.0 \pm 1.2 points, range: $0.8-6.0)$ and the lowest for desire (4.1 \pm 1.2 points, range: $1.2-6.0$ ) (Table 2 ). As many as $34.1 \%$ of the participants scored fewer than 27.5 points.

As shown in Table 3, statistically significant correlations between age, BMI, age of the menarche, age of sexual initiation and FSFI scores were observed for the following:

- age and desire - the older the women, the lower the scores for the desire domain $(R=-0.28$, a weak negative correlation),

- age of menarche and desire - the later the age of menarche, the lower the scores for the desire domain $(R=$ -0.22, a weak negative correlation),

Table 1. General characteristics of the study subjects; $n=91$

\begin{tabular}{lccc}
\hline Variables & Mean \pm SD & Median (range) & $n(\%)$ \\
\hline Age [years] & $24.3 \pm 4.0$ & $23.0(20-35)$ & \\
\hline BMI $\left[\mathrm{kg} / \mathrm{m}^{2}\right]$ & $21.72 \pm 2.98$ & $21.26(16.73-33.50)$ & \\
\hline $\begin{array}{l}\text { Menarcheal age } \\
\text { [years] }\end{array}$ & $12.7 \pm 1.5$ & $13.0(10-18)$ & \\
\hline $\begin{array}{l}\text { Age of sexual } \\
\text { initiation [years] }\end{array}$ & $18.2 \pm 2.4$ & $18.0(13-28)$ & \\
\hline $\begin{array}{l}\text { Oral } \\
\text { contraceptives }\end{array}$ & Yes & & $54(59.3)$ \\
\cline { 2 - 4 } & No & $37(40.7)$ \\
\hline FSFI [points] & $<27.50$ & $31(34.1)$ \\
\cline { 2 - 4 } & $\geq 27.50$ & $60(65.9)$ \\
\hline
\end{tabular}

Source: the authors' own research.
Scores for the particular domains and FSFI total were positively correlated:

- desire and arousal $-R=0.42$, moderate positive correlation,

- arousal and lubrication $-R=0.71$, strong positive correlation,

- arousal and orgasm $-R=0.70$, strong positive correlation,

- arousal and satisfaction $-R=0.57$, moderate positive correlation,

- lubrication and orgasm $-R=0.55$, moderate positive correlation,

- lubrication and satisfaction $-R=0.43$, moderate positive correlation,

- lubrication and pain $-R=0.46$, moderate positive correlation,

- orgasm and satisfaction $-R=0.59$, moderate positive correlation,

- FSFI and all its domains ( $R$ range from 0.57 to 0.85 ).

A weak positive correlation was found for the age of the respondents, BMI, age of menarche and the age of sexual initiation.

No statistically significant correlations were observed for the remaining variables (Table 3).

The mean FSFI scores for almost all of the domains and the FSFI total were higher for women taking oral contraceptives, although statistically significant differences were detected only for the orgasm domain (Table 4).

\section{Discussion}

As mentioned in the introduction, one of the most important issues in maintaining sexual health is STI prevention, early diagnosis, screening and appropriate treatment. STI are still emerging issues in gynaecology and venereology. Its acquisition is influenced by socioeconomic, psychological and cultural factors, and represents a significant concern for health care and societies.

The FSFI survey used in the pilot study enables the assessment of one of the important STIs risk factors, i.e. the age of sexual initiation. At the same time, the FSFI is used to assess the quality of women's sexual life, significantly

Table 2. Descriptive statistics of scores for FSFI domains and FSFI total in the study participants; $n=91$

\begin{tabular}{lccccc}
\hline FSFI domain & Mean & SD & Median & Min. & Max. \\
\hline Desire [points] & 4.1 & 1.2 & 4.2 & 1.2 & 6.0 \\
\hline Arousal [points] & 4.6 & 1.3 & 5.1 & 0.0 & 6.0 \\
\hline Lubrication [points] & 4.7 & 1.4 & 5.1 & 0.0 & 6.0 \\
\hline Orgasm [points] & 4.4 & 1.5 & 4.8 & 0.0 & 6.0 \\
\hline Satisfaction [points] & 5.0 & 1.2 & 5.2 & 0.8 & 6.0 \\
\hline Pain [points] & 4.7 & 1.6 & 5.2 & 0.0 & 6.0 \\
\hline FSFI total [points] & 27.4 & 6.5 & 29.3 & 3.8 & 35.1 \\
\hline
\end{tabular}

Source: the authors' own research. 
Table 3. Spearman's rank correlation coefficients for the quantitative variables; $n=91$

\begin{tabular}{|c|c|c|c|c|c|c|c|c|c|c|}
\hline Variables & BMI & $\begin{array}{l}\text { Menarcheal } \\
\text { age }\end{array}$ & $\begin{array}{l}\text { Age of sexual } \\
\text { initiation }\end{array}$ & Desire & Arousal & Lubrication & Orgasm & Satisfaction & Pain & $\begin{array}{l}\text { FSFI } \\
\text { total }\end{array}$ \\
\hline Age & $0.38^{*}$ & $0.34^{*}$ & $0.22^{*}$ & $-0.28^{*}$ & -0.15 & -0.15 & -0.12 & 0.02 & 0.00 & -0.12 \\
\hline BMI & & 0.10 & 0.08 & -0.05 & 0.00 & 0.00 & 0.02 & -0.0 & 0.08 & 0.02 \\
\hline \multicolumn{2}{|c|}{ Menarcheal age } & & 0.09 & -0.22 & -0.20 & -0.15 & -0.17 & -0.03 & -0.09 & -0.19 \\
\hline \multicolumn{2}{|c|}{ Age of sexual initiation } & & & -0.10 & 0.07 & -0.04 & 0.03 & 0.04 & -0.03 & 0.00 \\
\hline \multicolumn{2}{|l|}{ Desire } & & & & $0.42^{*}$ & $0.32^{\star}$ & $0.37^{\star}$ & $0.27^{\star}$ & 0.16 & $0.57^{\star}$ \\
\hline \multicolumn{2}{|l|}{ Arousal } & & & & & $0.71^{*}$ & $0.70^{*}$ & $0.57^{\star}$ & $0.39^{\star}$ & $0.85^{*}$ \\
\hline \multicolumn{2}{|l|}{ Lubrication } & & & & & & $0.55^{\star}$ & $0.43^{*}$ & $0.46^{\star}$ & $0.80^{*}$ \\
\hline \multicolumn{2}{|l|}{ Orgasm } & & & & & & & $0.59^{*}$ & $0.34^{*}$ & $0.78^{*}$ \\
\hline \multicolumn{2}{|c|}{ Satisfaction } & & & & & & & & $0.31^{*}$ & $0.69^{\star}$ \\
\hline \multicolumn{2}{|l|}{ Pain } & & & & & & & & & 0.60 \\
\hline
\end{tabular}

*Statistically significant, $p<0.05$. Source: the authors' own research.

extending the gynaecological and sexual health medical interview. This questionnaire should be therefore of a routine use in sexology, gynaecology, and venereology.

Moreover, there is a well-documented association between an early sexual debut and the risk of developing cervical cancer as immature, metaplastic cervical epithelium is particularly sensitive to oncogenic effects of HPV.

The broadly understood name of STD was adopted by the WHO in 1974 replacing the traditional name of venereal diseases, covering many diseases caused by pathogens transmitted through sexual contact with a characteristic location within the genital organs [17].

The WHO estimates that approximately 1 million people become infected with STD each day, and 376 million new infections are due to one of four STD: chlamydia, gonorrhoea, syphilis and trichomoniasis.

The study offers the possibility to check how factors such as age, BMI, age of menarche, oral contraceptives, and age of sexual initiation influence women's sexual function.

The results suggest that rising age negatively affects the women's desire domain. Desire was also the domain with the lowest score obtained in the survey. It is widely confirmed that increasing age and menopause are associated with a more frequent occurrence of health problems disturbing female's healthy sexuality [18-21]. The results of a study of an older cohort of women (40-73 years of age) indicate that age and postmenopausal status negatively affect the arousal and lubrication domain of FSFI and overall sexual function. However, even in this study, general health affected sexual function less than interpersonal aspects such as emotional support and relationship satisfaction [22]. The subjects of our study were in the reproductive age and did not suffer from any general health problems, so their sexual function was more likely to be affected by psychosocial aspects. Although we did not collect data about the subjects' marital status, we may suspect
Table 4. Descriptive statistics and Mann-Whitney's $U$ test results for the FSFI domains and FSFI total among women taking or not taking oral contraceptives; $n=91$

\begin{tabular}{|c|c|c|c|c|}
\hline $\begin{array}{l}\text { Oral } \\
\text { contraceptives }\end{array}$ & $N$ & Mean & $\begin{array}{l}\text { Standard } \\
\text { deviation }\end{array}$ & $\begin{array}{c}P \text {-value (Mann- } \\
\text { Whitney' s } U \text { test) }\end{array}$ \\
\hline Desire [points]: & & & & 0.0629 \\
\hline Yes & 37 & 4.4 & 1.2 & \\
\hline No & 54 & 3.9 & 1.2 & \\
\hline Arousal [points]: & & & & 0.2717 \\
\hline Yes & 37 & 4.8 & 0.9 & \\
\hline No & 54 & 4.4 & 1.4 & \\
\hline Lubrication [points & & & & 0.0975 \\
\hline Yes & 37 & 5.0 & 1.1 & \\
\hline No & 54 & 4.5 & 1.6 & \\
\hline Orgasm [points]: & & & & $0.0481^{*}$ \\
\hline Yes & 37 & 4.6 & 1.3 & \\
\hline No & 54 & 4.2 & 1.6 & \\
\hline Satisfaction [points & & & & 0.5472 \\
\hline Yes & 37 & 5.1 & 1.0 & \\
\hline No & 54 & 4.9 & 1.3 & \\
\hline Pain [points]: & & & & 0.6958 \\
\hline Yes & 37 & 4.8 & 1.3 & \\
\hline No & 54 & 4.6 & 1.8 & \\
\hline FSFI total [points]: & & & & 0.1695 \\
\hline Yes & 37 & 28.7 & 5.1 & \\
\hline No & 54 & 26.5 & 7.2 & \\
\hline
\end{tabular}

*Statistically significant difference, $p<0.05$. Source: the authors' own research.

that some might have experienced a decrease in sexual function parallel to the duration of marriage, which was also observed by other authors [21, 23]. 
It is clear that almost all the domains of sexual function were positively correlated with each other. Desire was the domain with the lowest score obtained in the survey. Similarly, in the cohort of Jordanian women aged 18-69, the desire was the most commonly affected domain of FSFI [21].

Surprisingly, BMI index turned out to have no impact on sexual function in our study cohort. The majority of other studies have shown that a high BMI index is associated with impairments in sexual function [24, 25].

The age of menarche proved to be negatively correlated with the desire domain of FSFI. It is worth mentioning that some of the women reported delayed menarche (up to 18 years of age), which indicates that they might have suffered from constitutional delay of growth and puberty. According to the systematic review published by Zhu and Chan, this self-limited condition might potentially negatively affect adult psychological function [26].

Interestingly, the age of menarche was positively correlated with the age of the patients. It means that older subjects recalled a later age of menarche. This might be attributed to a downward secular trend in the age of puberty. A study carried out by Gomula and Koziel [27] revealed that after the political transformation in Poland in 1989 , a slow decrease in the age of menarche of Polish girls was observed. Aside from the trend towards earlier puberty, the age of sexual initiation also drops gradually in Poland, although not as radically as in Western Europe [28]. This was clearly demonstrated in the present study since older respondents reported a later age of sexual initiation.

Regarding oral contraceptives, there are conflicting data on their influence on libido. Several authors have reported negative effects of hormonal contraceptives on sexual function $[29,30]$, while in the present study and in some other studies, those who took oral contraception were less likely to have sexual dysfunction [31, 32].

Leaving aside the associations detected between the variables studied, a high percentage of women (34.1\%) presented with a total FSFI score below the cut-off value, which indicates a risk of sexual dysfunction.

Therefore, there are sound reasons for distributing the FSFI among patients and doctors of various medical specialties. This will enable screening women for sexual disorders and referring the patients at risk to sexual medicine specialists, also after treatment of STD.

It should be remembered that there are many defence mechanisms in order to protect the lower genital tract against pathogens while maintaining the physiological microbial flora. The most common microorganisms found in the vagina of women of the reproductive age include Lactobacillus bacteria (Lactobacillus crispatus, Lactobacillus jensenii, Lactobacillus gasseri), accounting for $90 \%$ of all bacteria colonizing the vagina. In addition, the acidic environment guarantees the growth of lactic acid bacteria, making it difficult for the multiplication and survival of microorganisms intolerant to low $\mathrm{pH}$. There is a correlation between the presence of $\mathrm{H}_{2} \mathrm{O}_{2}$-producing
Lactobacillus and a reduction in the incidence of HIV infection, gonorrhoea or bacterial vaginosis (BV) [33]. Epithelial cells constitute a mechanical barrier for microorganisms, they produce mucus, contribute to the death of infected cells through apoptosis or necrosis, and release cytotoxic substances. Moreover, they produce chemokines, cytokines, prostaglandins and stimulate humoral and cellular immune response [34]. Neutrophilic granulocytes show a protective effect against bacteria, fungi, protozoa and viruses through the presence of receptors recognizing microorganisms (TLR-1, -2, -4, -5, -6, -7, -8, -9 and -10) except for TLR-3. After binding to pathogenassociated molecular patterns (PAMPs), neutrophils, through their ability to phagocytosis, produce cytokines and chemokines, neutrophil extracellular traps (NETs) show anti-infective and pro-inflammatory effects [35]. On the other hand, NK cells (natural killers; a naturally cytotoxic cell) participate in immunoregulation processes.

Moreover, by means of the questionnaire, women themselves are able to assess their sexuality [10, 36]. There are some critical voices which appeared in the literature with regards to $\mathrm{FSFI}[37,38]$. The authors point out the issues not taken into account in psychometric components [10, 38]. First of all, it deals with issues apply the tools to people today sexually inactive. In history, the approach to sexuality in general has changed [39, 40].

The weak point of this research is that the study population is not a representative group for assessing sexual function in gynaecological practice, but this study is a preliminary one and will be continued. In the next part of the study, the authors plan to divide the population by age and to enlarge the study groups.

\section{Conclusions}

The FSFI survey used in the pilot study allows to demonstrate one of the important risk factors for STD, i.e. low age of sexual initiation, which is important in terms of gynaecology, sexology and venereology. A high percentage of Polish women of reproductive age presented with FSFI score below the threshold, which suggests sexual dysfunction. Among the factors examined, age and the age of menarche significantly affected women's desire, while oral contraceptives had an impact on the orgasm domain of sexual function. Gynaecological medical history could be extended to include issues related to female sexual function. The study needs to be continued in order to compare the results in an enlarged population, which would also be divided by age.

\section{Acknowledgments}

The authors wish to thank all the women who participated in the study, and everybody who assisted during the study. 


\section{Conflict of interest}

The authors declare no conflict of interest.

\section{References}

1. WHO, Sexual health and its linkages to reproductive health: an operational approach. Geneva 2017, World Health Organization. Retrieved from https://www.who.int/reproductivehealth/ publications/sexual_health/sh-linkages-rh/en/

2. Baumeister RF, Twenge JM, Cultural suppression of female sexuality. Review of General Psychology 2002; 6: 166-203.

3. Laumann EO, Paik A, Rosen RC. Sexual dysfunction in the United States: prevalence and predictors. JAMA 1999; 281: 537-44.

4. West SL, Vinikoor LC, Zolnoun DA, Systematic review of the literature on female sexual dysfunction prevalence and predictors. Annu Rev Sex Res 2004; 15: 40-172.

5. Rosen R, Brown C, Heiman J, et al. The Female Sexual Function Index (FSFI): a multidimensional self-report instrument for the assessment of female sexual function. I Sex Marital Ther 2002; 26: 191-208.

6. Pastwa-Wojciechowska B, Izdebski B. Sexual activity of Polish adults. Ann Agric Environm Med 2014; 21: 194-7.

7. Lew-Starowicz Z, Lukasiewicz M, Binkowska M. Sexuality of Polish women. Sexologies 2008; 17 (Supplement 1): 53.

8. Czajkowska KB, Lew-Starowicz Z, Szymańska M. The prevalence of sexual activity, and sexual dysfunction and behaviours in postmenopausal woman in Poland. Przegl Menopauz 2016; 15: 156-64.

9. Boroch J, Jarząbek-Bielecka G, Mizgier M, et al. Infantile and early childhood masturbation and adult masturbation. Med Rodz 2018; 21 (1A): 80-2.

10. Nowosielski K, Wróbel B, Sioma-Markowska U, et al. Development and validation of the Polish version of the Female Sexual Function Index in the Polish population of females. J Sex Med 2013; 10: 386-95.

11. Wiegel M, Meston C, Rosen R. The female sexual function index (FSFI): cross-validation and development of clinical cutoff scores. I Sex Marital Ther 2005; 31: 1-20.

12. Grover S, Shah R, Dutt A, et al. Prevalence and pattern of sexual dysfunction in married females receiving antidepressants: an exploratory study. J Pharmacol Pharmacother 2012; 3: 259-65.

13. Kowalczyk R, Skrzypulec-Plinta V, Nowosielski K, et al. Sexuality in women with polycystic ovary syndrome. Ginekol Pol 2015; 86: 100-6.

14. Sinica M, Jarząbek-Bielecka G, Pisarska-Krawczyk M, et al. Women's sexuality as surveyed by the FSFI questionnaire in those with no history of childhood sexual abuse or violence. J Health Inequal 2017; 3: 109-14.

15. Meston CM, Freihart BK, Handy AB, et al. Scoring and Interpretation of the FSFI: what can be learned from 20 years of use? J Sex Med 2020; 17: 17-25.

16. Neijenhuijs KI, Hooghiemstra N, Holtmaat K, et al. The Female Sexual Function Index (FSFI) - a systematic review of measurement properties. J Sex Med 2019; 16: 640-60.

17. Rowley J, Vander Hoorn S, Korenromp E, et al. Global and Regional Estimates of the Prevalence and Incidence of Four Curable Sexually Transmitted Infections in 2016. WHO Bulletin.

18. Tabatabaeichehr M, Mortazavi H, Abadi MH, et al. Sexual desire and related factors in middle-aged and elderly married women: a cross-sectional study in Iran. Open Access Maced J Med Sci 2018; 6: 1906-11.

19. Jarząbek-Bielecka G, Wilczak M, Potasińska-Sobkowska A, et al. Overweight, obesity and female sexuality in perimenopause: a preliminary report. Przegl Menopauz 2015; 14: 97-104.
20. Thornton K, Chervenak J, Neal-Perry G. Menopause and sexuality. Endocrinol Metabol Clin N Am 2015; 44: 649-61.

21. Maaita ME, Khreisat BM, Tasso OA, et al. Prevalence and associated risk factors of female sexual dysfunction among Jordanian women. J Fam Med Prim Care 2018; 7: 1488-92.

22. Mernone L, Fiacco S, Ehlert U. Psychobiological factors of sexual functioning in aging women - findings from the women 40+ healthy aging study. Front Psychol 2019; 13: 546.

23. Mishra VV, Nanda S, Vyas B, et al. Prevalence of female sexual dysfunction among Indian fertile females. J Mid-life Health 2016; 7: 154-8.

24. Sarwer DB, Hanson AJ, Voeller J, et al. Obesity and sexual functioning. Curr Obes Rep 2018; 7: 301-7.

25. Nascimento ER, Maia ACO, Pereira V, et al. Sexual dysfunction and cardiovascular diseases: a systematic review of prevalence. Clinics 2013; 68: 1462-8.

26. Zhu J, Chan YM. Adult consequences of self-limited delayed puberty. Pediatrics 2017; 139: e20163177.

27. Gomula A, Koziel S. Secular trend and social variation in age at menarche among Polish schoolgirls before and after the political transformation. Am J Hum Biol 2018; 30: e23048.

28. Durda-Masny M, Jarząbek-Bielecka G, Szwed A, et al. Trends over time in age at sexual debut among Polish women and underlying socio-economic determinants. Anthropol Anz 2018; 75: 185-91.

29. Sabatini R, Cagiano R. Comparison profiles of cycle control, side effects and sexual satisfaction of three hormonal contraceptives. Contraception 2006; 74: 220-3.

30. Sanders SA, Graham CA, Bass JL, et al. A prospective study of the effects of oral contraceptives on sexuality and well-being and their relationship to discontinuation. Contraception 2000; 64: 51-8.

31. Caruso S, Iraci SM, Agnello C, et al. Conventional vs. extendedcycle oral contraceptives on the quality of sexual life: comparison between two regimens containing $3 \mathrm{mg}$ drospirenone and 20 mg ethinyl estradiol. J Sex Med 2011; 8: 1478-85.

32. Pastor Z, Holla K, Chmel R. The influence of combined oral contraceptives on female sexual desire: a systematic review. Eur J Contracept Reprod Health Care 2013; 18: 27-43.

33. Sewankambo N, Gray RH, Wawer MJ, et al. HIV-1 infection associated with abnormal vaginal flora morphology and bacterial vaginosis. Lancet 1997; 350: 546-50.

34. Nasu K, Narahara H. Pattern recognition via the Toll-like receptor system in the human female genital tract. Mediators Inflamm 2010; 2010: 976024.

35. Borregaard N. Neutrophils: from marrow to microbes. Immunity 2010; 33: 657-70.

36. Bayoğlu TY, Ural ÜM, Üstüner I, et al. Evaluation of female sexual function index and associated factors among married women in North Eastern Black Sea region of Turkey. Turk J Obstet Gynecol 2014; 11: 153-8.

37. Forbes MK, Baillie AJ, Schniering CA. Critical flaws in the Female Sexual Function Index and the international index of erectile function. J Sex Res 2014; 51: 485-491.

38. Janus M, Szulc A. Sexological diagnostic tools in Poland and worldwide. Seksuol Pol 2015; 13: 31-5.

39. Boroch J, Jarząbek-Bielecka G, Filewski A, Kędzia W. Factors affecting the approach to autosexual behavior including the aspect of paediatric and adolescent gynaecology and family medicine in the context of historical conditions. Med Rodz 2019; 22: 88-95.

40. Laqueur TW. Lonely sex. Cultural history of masturbation. Towarzystwo Autorów i Wydawców Prac Naukowych "Universitas". Kraków 2006. 